\title{
Thinking Waste Sociologically
}

\section{Paul Hewer}

\section{Heavy Weather}

Troubled Times: wars raging and warfare taking new urban forms; democratic inertia and the failure of the civil; religious and political antagonisms on the march and gaining traction; networked whistleblowers confronting informational dictatorships; lifestyle choices of protected affluence driving climate change; and spinning-out of such contexts of adversity, practices of market reshapers and related social theorizers busy at work building discursive empires of scholarly advantage. In this brief addition to the volume, a work dug out from an incessant urge to practice a form of rethinking, an attempt is made to chart emerging processes of recalibration at work within global mixes of the visible and valuable, wherein the knots of the ecological imaginary undo themselves and their dark discourses of exigency and imperative.

Social theorizing is currently febrile in its intensity and desire to re-attune itself to such hazardous times, fetishizing narrow-gauge 'culture' as ever-ready panacea. Ulrich Beck's vision of a World at Risk (2009) perhaps best captures the current cultural moment and its' structuring of feeling:

"World risk society forces us to recognize the plurality of the world which the national outlook could ignore. Global risks open up a moral and political space that can give rise to a civil culture of responsibility that transcends borders and conflicts. The traumatic experience that everyone is vulnerable and the resulting responsibility for others, also for the sake of one's own survival, are the two sides of the belief in world risk." (2009, p.57)

A view echoed by Zygmunt Bauman (2010), for whom the writing is certainly on the wall:

"On a negatively globalized planet, all the most fundamental problems - the metaproblems conditioning the tackling of all other problems - are global, and being global they admit to no 
local solutions; there are not, and cannot be, local solutions to globally originated and globally invigorated problems." (2010, p.25-26).

Beck (2010) hits the nail firmly on the head when he suggests that: "The hardcore sociological question is: Where is the support for ecological changes supposed to come from, the support which in many cases would undermine their lifestyles, their consumption habits, their social status and life conditions in what are already very uncertain times? Or to put it in sociological terms: How can a kind of cosmopolitan solidarity across boundaries become real, a greening of societies, which is a prerequisite for the necessarily transnational politics of climate change?" $(2010$, p.255). Central to such a greening will be a rethinking of consumption practices as embedded within and woven into the everyday and its assemblages of desire, routine and habit. Commenting on the context of climate change, Shove (2010) explores the burdens these assemblages place on social theory as the necessity to "conceptualize and analyse processes of recruitment and defection: how do practices like those of showering on a daily basis capture us, their carriers? And how is it that people defect from others, like cycling or walking to work? These questions call for new ways of integrating micro, meso and macro levels of enquiry." (2010, p.283). What is therefore necessary is to practice a form of analysis which does not simply over prioritize the micro or the macro but to envisage how actions are enfolded and enframed within the orbit of larger forces so as to move beyond the construct of the consumer self as "bounded, individualized, intentional, the locus of thought, action, and belief, the origin of its own actions, the beneficiary of a unique biography." (Rose 1998, p.3). It is towards an understanding of how market-ing practices may be recalibrating the environmental imaginary that the paper now turns. 


\section{Market Reshaping and the Spirit of Sustainable Invention}

For Beck (2009), it is management and marketing that stands squarely in the dock; capitalism and its incessant urge for innovation and market opportunity to blame for our current troubles:

"All past and present practical experiences in dealing with uncertainty can claim equal justification; however, for that very reason they do not offer a solution to the resulting problems. More than that, key institutions of modernity, such as science, business and politics, which are supposed to guarantee rationality and security, are confronted with situations in which their apparatus no longer has any purchase and the basic principles of modernity no longer hold automatically. As a result, these institutions are being judged completely differently - no longer as trustees but as suspects. They are no longer seen as managers of risk, but also as sources of risk." (2009, p.54).

But then as solution providers and peddlars in myth, hope and transformation, marketers have not been shy in seizing the market opportunities which such a climate of uncertainty generates; offering up new philosophies of eco-consuming to curtail such doubts and offer a measure of hope. Trendwatching.com a consultancy firm whose business it is to track emergent cultural trends are thus quick to spot the trend for 'Guilt-free consumption' and 'Eco-superior'. Products and branding are thus positioned to engage us in an intimate and persuasive conversation around ready-made solutions to such problems of uncertainty. Talk of sustainability has thus become the new language game, not the only game in town but an easy sell in hazardous times. From the hybrid to the DreamWorlds offered up in the advertising of 'new' cars which are advertised with their $\mathrm{CO}_{2}$ and eco-credentials to the fore. Another example is how such concerns filter into games, a great way of reimagining the world as it is and imaging change, for example Top Trumps games like eco-action which aim to produce new forms of practical consciousness and awareness centred on an ethic of 
'Play. Learn. Discover your ecoworld.' See also McDonagh \& Prothero (this volume) for more on this theme of the websiting of sustainable conversations.

Coupled with such attempts to recalibrate our understanding of consumption as other to its identity-status-driven form where the new is cherished for its power to inspire and innovate will be a heightened sensitivity to everyday routines, such as showering (Shove, 2010), staying warm (Jalas and Rinkenen 2013), sorting trash, or domestic water consumption (Vannini and Taggart 2013), a trend that is likely to witness ever more consumption practices scrutinised and subjected to metered surveillance and micro-management. The reinvention of frugality as an ethos of 'smart' consumption is slowly gaining traction in ways that 'downshifting' has been unable to because of its connotations of sacrifice, denial and sect when set against the more immediately visible and available secular gratifications of easy (irresponsible) consumer lifestyling. Disengaged consumption, where chains of impact and import remain uncontested reveals myopia at the heart of everyday lifestyle practices of accountability. We argue that Miller's notion of shopping as 'making love' (1998) indicates the scale of disconnect operating at the level of the everyday domestic, where taken for granted often poses as essential. An imaginary that generates its own forward motion through essentialisms of making love manufactures its own justifications too. And while the warp and weft of everyday life draws upon assemblages of essentialisms and justifications, routines and habits, must-dos and lists of priority, it remains impervious to recalibration as long as the priority is on the individual or the sheltered therapeutic of a home over-protected from larger forces of change.

A less blasé attitude towards impact and import may prove increasingly pervasive, driven by the growing expression of climate cost through media of economic imperative. Macro forces will engender increased concern around a rethinking of the desire to make easy the sometimes troublesome and troubling routine solutions to the trials of everyday. For example, when switching on a light or a heater will become a moment of reflexivity: a moment of heightened self-awareness, 
a moment of self-accounting, a moment of metered behaviour for the character of impact and import that such routine actions calls into being. Possibly, the reflexive consumer lifestyle will problematize the autonomy and unspoken privilege of the individual actor as a buyer or even consumer, reframing the naïve autonomy that informs the idea of the self as a necessary site of buying privileges and market solutions. Such reflexive moments and their ontological uncertainties and self-accountings, suggest a technology of being that calls anew upon the politics of experience as ecological narcissisms: so much so that new passions may emerge centred on an eco-logic of costsaving, energy reduction and the desire to desist from disengaged irresponsible consumption. Treading lightly will thus take on a new urgency and appeal, producing its own forms of standing out, its own local cultures of taste and conformity, with the 'home front' becoming the battleground for such a rethinking of how lifestyling may be better practiced. In this climate new forms of practical and eco-consciousness may surface driven by a range of forces. One such force will be the shift towards new forms of metered existence. Here diagnostics will take centre-stage to assemble new platforms of performativity. Perhaps the mantra of the cover - re-use, recycle and refrain appears more in tune and relevant in an era of global uncertainty and the responsibilities brought in the wake of such a realisation. Such a vision of eco-Utopia will be better publicised, distributed and communicated through media platforms in search of an audience desiring to participate. Social media and TV programmes with their in-built reaching out and glamourising potential will perhaps better underscore the necessity, or even the advantages to be claimed through recalibrating one's routines and habits. Through such cultural forms change will be possible.

Closer to home we witness how the local re-sensitizes us to global problems. Take for example Greener Scotland an organisation set up with a transformative agenda of inspiring a population to turn to living greener. Here the call to arms is participatory almost tribal in its mantra of: 'Let's Go Greener Together': 
“Greener living is a great way to build a cleaner and greener Scotland. What we've done so far has already had an effect, but we can do much more if we join together. We can have a huge impact on the wellbeing of our families, the comfort of our homes, the quality of the places we live, and the health of the natural environment around us. Greener living also helps us to play our part as one of the wealthiest countries in the world. We must all do what we can to reduce carbon emissions and slow down climate change. And if we look after the planet, we look after Scotland too. Cleaner air. Warmer homes. Less noise. Less pollution. Better health and fitness. It all adds up to a better quality of life."

The website offers up a range of greener solutions around saving energy, greener travel, greener eating to translate the science of waste and reduction into a set of easy recipes for change. From advice on 'what can I recycle' to explaining the manifesto of reduce, reuse and recycle: "By reducing waste, choosing goods that last and recycling those things we can't reuse or repair, we can all make a real difference to the environment we share." (www.greenerscotland.org.reduce-reuse-recycle). Here the discourse of Greener Together offers something akin to Connolly and Prothero's green consumption as life politics (as inspired by Giddens) where as they suggest: "The question of, 'How shall I live?' has to be answered in day-to-day decisions about how to behave, what to wear and what to eat and numerous other things, as well as interpreted within the temporal unfolding of selfidentity." (2008, p.131). Consumer culture reimagining itself perhaps, the everyday being rethought beyond habit and routine and the reawakening of politics and ethics, in the forms of the sayings and doings we tell ourselves, as central to understanding consumption and its consequences.

\section{The Tango of Rationalization and Romanticism}

For Beck (2009), Max Weber's Protestant Ethic thesis must be furthered, or as he suggests:

"According to Weber, the globalization of risk is not bound up with colonialism or imperialism and hence is not driven by fire and the sword. Rather it follows the path of the unforced force 
of the better argument. The triumphal procession of rationalization is based on the promised utility of risk and on the corresponding rational restriction of the side effects, uncertainties and dangers bound up with it...However, the idea that precisely the unseen, unwanted, incalculable, unexpected, uncertain which is made permanent by risk, could become the source of unforeseen possibilities and threats that effectively place in question the idea of rational control - this is inconceivable on the Weberian model." $(2009$, p.17)

Echoes here of the work of Colin Campbell (1987) comes to mind with his incisive analysis of how ideals affect and are performed in practical conduct. Here the turn back to Campbell is necessary, for his thesis demonstrates that Weber's tale missed a vital ingredient, that the rendering of the iron cage of rationality and necessity masks a romantic spirit which dances to a different tune to that of strategy and calculation; a spirit best conjured in the desire to day-dream and fantasize. Is there a role for such self-illusory hedonism in a marketized culture of individual rage, narcissistic urge and immediate gratification? Whence comes anew the ecological imaginary of the frugal, of the treading lightly and related spaces of domestic practices of reflexivity and accounting: sidelined, erased, defeated by arguments of power and the status quo; or, do such forms of consumption simply go underground to resurface when most in demand. Not difficult to see how musical forms will express such ideals. How the rhythm and moment of romanticism is best articulated through alternative forms of expression. The most obvious example would be music and its ability to conjure up a mood a feeling, a context through sound. But advertising and branding, the twin tools of the marketing imaginary, sometimes provide alternative imagining solutions, spinning tales of hope and transformation that are hard to disavow. Salvation in an age of uncertainty and a world of everincreasing risks appears to be centred on the shift to sustainable consumption. Such a shift borne on the tides of many an advertising campaign for the latest eco-product suggests that it is in the spirit of eco-logic that salvation may reside. That it is through sustainable consumption and a rethinking of everyday routines that hope may lie. From Beck's (2009) questioning of rational thinking and the anticipation of risks as the force of current times to a recognition that while market practices may 
sometimes serve to heighten our sensitivity to such risks and problems, at other times such practices serve to quell and calm our sensitivity towards such risks offering a measure of amelioration to displace anxiety. The visual aesthetics of 'going green' express the iconography of sustainability and recycling as one of hope and transformation for commercial gain and personal adventure.

\section{Waste \& Disposal}

Waste announces itself through its facticity, through its sheer scale and the quantitativity of sheer numbers. In this game we are all entangled and complicit. Waste buttonholes us into political economy, the heavy-duty of social re-engineering and the mechanics of social reproduction; where culture squares up to the brute forces of economics, global politics and management.

Horizon 2020 the European Commission's new blueprint for climate action captures and performs the emerging paradigm of discourses around 'waste' as a resource to recycle, reuse and recover raw materials:

\footnotetext{
"A smart economy minimises the production of waste and reuses waste as a resource. Resource constraints and environmental pressures will accelerate the transformation from a linear extraction-use-throw away model of production and consumption to a circular one. Moving towards a near-zero waste society not only has an environmental rationale, it increasingly becomes a factor of competiveness. Europe has proven expertise in efficiently handling and treating waste and is at the forefront of innovation in this sector. Capitalising on these strengths, this call intends to further boost innovative, environmentally-friendly and cross-sectional waste prevention and management solutions." (EU, Horizon2020 Work Programme 2014-2015).
}

Here 'waste' becomes the great rescuer, the great hope, the means by which a troubled Europe will re-establish its position as 'world marker leader' for as the report opens: "The global waste market, from collection to recycling, is estimated at EUR400 billion per annum and holds significant potential 
for job creation. The old adage that there's gold in muck or even every cloud has a silver lining holds true. Or as the call to action (and grant salvation) continues: "Industrial symbiosis, whereby different actors derive mutual benefit from sharing utilities and waste materials, requires large-scale systemic innovation with the aim of turning waste from one industry into useful feedstock for another one." (ibid, p.8). The language of impact, innovation and action are to the fore with ambitious targets set to reduce food waste by $50 \%$ by 2030 , to reduce waste management costs and towards "sustainable food consumption patterns leading to healthier consumers and as a result reduced national health costs." A trip to the UK Government website for the Environment, Food and Rural Affairs reveals a similar tale of generating energy from waste with the management of waste as the new holy grail of governmentality: "The UK is obliged under the revised EU waste Framework Directive to apply the waste hierarchy. This ranks waste management options in order of environmental preference and the first priority is waste reduction." (www.gov.uk/generating-energy-from-waste-includinganaerobic-digestion).

What strikes the author is the absence of theorizing consumption from such policy-making debates of impact, instead for the EU the talk is much more of the effort to model business and consumer behaviour or through discussion of what are termed 'eco-innovative strategies' whereby proposals must highlight 'how urban patterns, drivers, consumer behaviour, lifestyles, culture, architecture and socio-economic issues can influence the metabolism of cities' (ibid, p.16). What price hope and understanding in a world where modelling is to the fore; where quantitativity and the self-assurances it brings wins the day and better argument. Here as Bauman foretold "Salvation is in numbers." (2004, p.121). But what remains absent and erased is the recognition, which Miller (1995) in his discussion of consumption as the vanguard of history, so well foretold, that consumption remains first and foremost "a social, cultural and moral project". That is, an embedded assemblage of practices through which the pressures of politics and economics, the pressures of the everyday, of routines and habits are enfolded and speak us into being. Such a form of analysis brings with it an in-built sensitivity to life politics and to qualities over quantities. But more so, that it is 
only through understanding such shifting and fixed consumption practices that we glimpse how life unfolds in contested forms, how life flows in unintended ways ever responsive to shifting macro, micro and meso forces.

Such an acknowledgement that consumption, culture and lifestyle remain the crucial ingredients for a recipe for change and understanding is at least distinct from the talk of the post-consumer concept which one finds mobilised within the waste management literature. This is a significant field of academic inquiry which mainly hails from the heft and might of Environmental Sciences and Engineering and Manufacturing. With its own journals, favoured concepts and methodologies, the disconnect you witness here from consumer research startles, the disconnect from consumption as a social form is abrupt. One such concept deployed in this disciplinary field is that of the postconsumer and its attendant forms of post-consumer waste. Here post-consumer is defined in final and fixed and closed terms as simply end-of-life, no space here to acknowledge the social life of things (Appadurai, 1986). For example, Staikos and Rahimifard (2007) discuss trends in the global footwear industry which witnessed a 70\% increase in footwear production from 1990 to 2004, with worldwide footwear production and consumption doubling every 20 years from around 2.5 billion in the 1950 s to 20 billion pairs in 2010 . The challenge here is an environmental one; that is the waste generated in this post-consumer phase with most shoes ending up in landfills. But it is also a problem of design and product development; that is the different materials which are combined to produce a shoe fit for purpose and which subsequently become difficult to separate. Likewise Domina and Koch (1999) report on post-consumer textiles waste: "garments or household articles made of textiles that the owner no longer needs and decides to discard." (1999, p.347); revealing that most households recycle textiles with the most common form of disposition being to charity shops, family and friends or using as rags. Whereas Ekstrom et al (this volume) suggest that most clothes are not recycled or passed on in such ways but destined for the dustbin. 
Another example of such post-consumer modelling in action can be found in the work of Staikos and Rahimifard's (2007) waste management framework. This highlights a range of options for footwear from the proactivity of waste minimisation achieved through design and material improvements, to reactive end-of-life management approaches with its focus on reuse, recycling, energy recovery and disposal. Here talk is of value recovery chains and the new market opportunities to develop through the market for recyclable materials $(2007, p .365)$. While for Huhtala (1997), "The percentage of waste recycled can be raised by increasing the participation rate of households in recycling programs and by increasing the number of waste items that can be reused, such as paper, aluminium, glass and plastic." (1997, p.302).

The absence of theorizing consumption here is troubling, not least from those diggers with a vested interest in such a topic, but also concern arises from the forms of knowledge produced around an understanding of waste when it is not adequately theorised through the lens of consumption. Here it is necessary to concur with Wilk (2002), for whom hope lies in identifying what he regards as the three major paradigms within consumption theory (individual choice, social, and cultural theories of consumption) before outlining a Bourdieusian example based around theories of practice. Such an approach takes seriously notions of habitus, praxis and heterodoxy. Additionally as part of this broadening of the conversation around consumption practices and their theorizing it is useful to turn to work on disposal practices (Hetherington 2004; Munro 2013).

For example, Hetherington (2004) argues against the term waste for its negative implications of closure and lack of sensibility towards its "dynamic and performative role within consumption." (2004, p.159). Here the value of disposal reveals itself through rethinking the ways that people do "membership and identity work" through not only practices of acquisition, but also "how they dispose of consumed objects." (2004, p.167). Encouraging us then to think sociologically about disposal practices, Hetherington teases out the importance of "how we manage absence - how we order it, place it, when we use it as a source of value" $(2004$, p.170). Here the focus is much more on 
the forms of organizing and order-building made possible through such value judgements. For Munro (2013), much like Hetherington (2004), "Disposal is typically related in the literature negatively - to waste... [but] the meanings of disposal in its everyday sense of material arrangement and placing are elided and, with this, much of the moral ordering of place and space is overlooked." (2013, p.214-215). Later in this insightful article Munro likens his proposal to a rethinking of sociology: "We need to do more than refine waste products as recyclable, as if we could re-instate the marginalized, and excluded back to their proper place in society. We need to find ways, as well, to challenge how it is that systems of production 'outcast' materials and morals as useless, outdated, or even immobile. It is not enough to try to 'balance out' the cast-offs of production and consumption perspectives by pointing to human rights, or by recourse to markets offering compensation." (p.225). Here disposal practices are re-theorized as the placing and arranging of things to better reveal their intimate link with the moral framing of our worlds. The morality of waste and recycling better attunes us to how such practices are part and parcel of the everyday and involve us in dilemmas over choice, value and oversight. Discourses of waste then unfold as ontological and social dilemmas to be acted upon or cast aside as insignificant or vital to the assembling of ourselves (cf. Rose 1998). So the opportunity and need for greater conversations between disciplines such as the social sciences and mechanical and chemical engineering certainly looks like an increasing necessity, given the shared concerns and contrasting modes and styles of theorizing, an opportunity which the discussions in Boras in 2013 valiantly kick-started.

\section{Conclusion}

And so it is here, that the digging of this chapter closes, not with statistics, or the brute forces of economic endeavouring but with leftovers and the flickering of hope. To practice that is a form of theorizing around consumption and its consequences as inspired by Miller (1998) and Bauman (2004). For as Bauman and May (2001) suggest: "Sociological thinking, as an antifixating power, is 
therefore a power in its own right. It renders flexible what may have been the oppressive fixity of social relations and in so doing opens up a world of possibilities." (Bauman \& May 2001: 11). A paper dug out then from contexts of adversity, cultivated to practice a form of thinking and theorizing around notions of waste and disposal which better captures the spirit of reinvention and recycling at work. And so it is here, to poetics as a form of rethinking the unforeseen and the unintended that the paper closes.

By way of illustration, let us return to Bauman (2004) on Wasted Lives: Modernity and its Outcasts. In this illuminating work around notions of waste and societing, he offers up two images of designs around waste, those of mining and farming (cf. Bauman 2004, p.20-22). Two designs and recipes for living offered up by the social theorist busy at work theorizing and labouring. For Bauman, farming speaks of continuity; whereas mining speaks of rupture and discontinuity. But perhaps we should add a third image to these compelling designs, modes of organization and forms of order-building, that of gardening. To garden speaks less of mining or farming, less of rupture but instead of labours, remembrance and futures possible, on the here and now and the what could be. To garden speaks of continuity, but its expresses alternative forms of production, less tied to notions of strategy, calculation and profit. To garden does not demand a balance sheet of equities and taxes. To garden is a moral practice with in-built social tendencies. To garden is to assemble, to place and to arrange things. To garden is to be in tune with the passing of time, to sensitize oneself to collective endeavour through acts of caring and doing. To garden speaks of practices of digging and composting, of value as expressed in forms of making-do and doing. In the garden 'waste' is recycled and re-used. Recycling expresses itself through routine and habit. In the garden death, decomposition and tragedy are never far. In the garden the unforeseen and the unintended happen through happenstance as much as design.

For a glimpse into such practices of garden making at work, I urge you to take a look at the gardens of the homeless as documented in Balmori and Morton's Transitory Gardens, Uprooted 
Lives (1993) where they suggest: "In the reuse of nearly everything discarded, the sparing use of water, and the economical treatment of space, these gardens speak the language of our time. We are admonished to recycle, to conserve, to make maximum use of scarce of natural resources. Here all of these admonishments are heeded by necessity, under extreme conditions, and the result is the elevation of such things as water and living plants to precious, valued elements. Ironically, it is through this necessity that the suffering underlying it that a respect for natural resources has emerged in these gardens." $(2004$, p.7).

To garden is then a form of politics borne of the desire for worlding and reassembling oneself. To garden speaks of power and affluence, but equally of vulnerabilities and forms of exclusion and inclusion. To garden is then to open oneself up to a world of possibilities; a world of hope, colour, beauty and transformation. In the garden we dwell.

\section{Acknowledgement}

This paper could not have been written without the guidance and inspiration of Professor Douglas Brownlie. The author would also like to thank Professor Karin Ekström for her generous invitation to join the conversation and the stellar participants at the University of Borås workshop (Sweden) for their spirit, energy and knowledge on this subject. 


\section{References:}

Appadurai, Arjun (2010, orig.1986), "Commodities and the politics of value," in: Arjun Appadurai (ed.) The Social life of things: commodities in cultural perspective, Cambridge: Cambridge University Press, 3-63.

Balmori, Diana and Morton, Margaret (1994), Transitory Gardens, Uprooted Lives, New Haven: Yale University Press.

Bauman, Zygmunt (2010), Liquid Times: Living in an age of uncertainty, Cambridge: Polity.

Bauman, Zygmunt (2004), Wasted Lives: Modernity and its Outcasts, Cambridge: Polity.

Bauman, Zygmunt and May, Tim (2001), Thinking Sociologically, Oxford: Blackwell.

Beck, Ulrich (2009), World at Risk, Cambridge: Polity.

Beck, Ulrich (2010), "Climate for Change, or How to Create Green Modernity," Theory, Culture and Society, 27 (2-3), 254-266.

Becker, Howard (1997, orig. 1963), Outsiders: Studies in the Sociology of Deviance. New York: Simon and Schuster Ltd.

Bramall, Rebecca (2013), "The austerity larder: Mapping food systems in a new age of austerity," Journal of Consumer Culture, published online $4^{\text {th }}$ July 2013.

Campbell, Colin (1987), The Romantic Ethic and the Spirit of Modern Consumerism, Oxford: Basil Blackwell.

Connolly, John and Prothero, Andrea (2008), "Green Consumption: Life-politics, risk and contradictions," Journal of Consumer Culture, 8 (1), 117-145.

Domina, Tanya and Koch, Kathryn (1999), "Consumer reuse and recycling of post-consumer textile waste," Journal of Fashion Marketing and Management, 3 (4), 346-359. 
Gile, Zsuzsa (2013), "From Risk to waste: global food waste regimes," The Sociological Review, 60 (2), $27-46$

Hawkins, Gay (2013), "The Performativity of food packaging: market devices, waste crisis and recycling," The Sociological Review, 69 (2), 66-83.

Hetherington Kevin (2004), "Secondhandedness: consumption, disposal, and absent presence," Environment and Planning D: Society and Space, 22(1) 157- 173.

Jalas, Mikko and Rinkinen, Jenny (2013), "Stacking Wood and staying warm: Time, temporality and housework around domestic heating systems," Journal of Consumer Culture, published online $11^{\text {th }}$ November 2013.

Miller, Daniel (1995), "Consumption as the vanguard of history: A polemic by way of an introduction". In: Daniel Miller (ed.) Acknowledging Consumption: A Review of New Studies, Oxford: Routledge, 1-57.

Miller, Daniel (1998), A Theory of Shopping, Cambridge: Polity Press.

Munro, Rolland (2013), "The disposal of place: facing modernity in the kitchen-diner," The Sociological Review, 60 (2), 212-231.

Rose, Nikolas (1998), Inventing Our Selves: Psychology, Power and Personhood, Cambridge: Cambridge University Press.

Sahakian, Marlyne and Wilhite, Harold (2013), "Making practice theory predictable: Towards more sustainable forms of consumption", Journal of Consumer Culture, published online $9^{\text {th }}$ October 2013. Shove, Elizabeth (2010), "Social Theory and Climate Change," Theory, Culture and Society, 27 (2-3), 277-288. 
Smart, Barry (2011), "Another 'Great Transformation' or Common Ruin?," Theory, Culture and Society, 28 (2), 131-151.

Staikos, T. and Rahimifard, S. (2007), "Post-Consumer Waste Management Issues in the Footwear Industry," Proceedings of the Institution of Mechanical Engineers, Part B: Journal of Engineering Manufacture, 221, 363-368.

Vannini, Phillip and Taggart, Jonathan (2013), "Onerous Consumption: The alternative hedonism of off-grid domestic water use," Journal of Consumer Culture, published online $11^{\text {th }}$ November 2013.

Wilk, Richard (2002), "Consumption, human needs, and global environmental change," Global Environmental Change, 12, 5-13. 